\title{
Characterization of Plasticized PEO Based Solid Polymer Electrolyte by XRD and AC Impedance Methods
}

\author{
K. Ragavendran, * P. Kalyani, A. Veluchamy, S. Banumathi, \\ R. Thirunakaran, T.J. Benedict
}

Central Electrochemical Research Institute, Karaikudi 630 006, India.

Received 5 August 2003; accepted in revised form 8 January 2004

\begin{abstract}
The ionic conductivity of lithium based solid polymer films prepared from poly (ethylene oxide) (PEO) and lithium hexafluoarsenate $\left(\mathrm{LiAsF}_{6}\right)$ with varying compositions of plasticizers like dibutyl sebacate (DBS) and ethylene carbonate (EC) was measured by $\mathrm{AC}$ impedance method. Polymer film composition viz. (PEO) ${ }_{8}-$ $\mathrm{LiAsF}_{6}-(\mathrm{DBS})_{0.4}-(\mathrm{EC})_{0.1}$ has been evaluated as an optimum composition as evidenced from its high conductivity and freestanding ability. The high conductivity observed for the polymer electrolyte with this composition has been attributed to an enhanced amorphous character and a reduced energy barrier to the segmental motion of lithium ions in the matrix. The temperature dependence of conductivity on the polymer films, with and without plasticizers, appears to obey the Arrhenius law. However, the activation energy of the plasticized polymer film is $0.81 \mathrm{KJ} / \mathrm{mol}$, a value considerably lower than $10 \mathrm{KJ} / \mathrm{mol}$ obtained for the unplasticized electrolyte, making the polymer to be a prospective candidate as lithium-ion conducting electrolyte for rechargeable lithium batteries.
\end{abstract}

Keywords: plasticizer, solid polymer electrolyte, conductivity, dibutylsebacate.

\footnotetext{
* Corresponding author. E-mail address: raguelectro@rediffmail.com
} 


\section{Introduction}

Thin film batteries are recent invention and hence are of considerable interest for applications in various miniature electronics such as cellular telephones, smart credit cards, etc. [1-4]. These batteries can readily be fabricated from polymerelectrolyte-based cells. This has been made possible by the pioneering research of Fenton et al. [5] on ionically conducting polymer electrolytes as early as 1973. These authors showed that complexes formed with poly ethylene oxide (PEO) and alkali metal salts exhibit higher ionic conductivity at elevated temperature than the conductivity of the films at lower temperatures. Subsequently, these complexes were proposed by Armand et al. [6] as electrolytes for solid-state lithium battery applications using lithium salts. Extensive reviews discussing the formation, structure, morphology and transport theory of PEO complexes have been published [7,8]. Berthier et al.[9] established that the ionic conductivity of polymer electrolytes has a specific dependence on the amorphous nature of the samples. One of the most successful approaches to increase the amorphous nature, and hence the ionic conductivity, has been to incorporate suitable plasticizer(s) into the polymer matrix $[10,11]$. The selected plasticizers should be such that the low viscosity and high dielectric nature of these materials may effectively lower the potential barrier to the lithium ion transport and may tend to dissociate into anions and cations (as ion pairs), thus resulting in higher conductivity [12].

A polymer electrolyte consisting of PEO, an alkali metal salt and poly(ethylene glycol dimethylether) (PEGDME) as plasticizer has been shown to exhibit an ionic conductivity of about $10^{-4} \mathrm{~S} \mathrm{~cm}^{-1}$ at $40{ }^{\circ} \mathrm{C}$ [13]. Conductivity data on PEO electrolyte with propylene carbonate (PC) as plasticizer were also reported by Munshi and Owens [14]. Ballard et al. [15] recently reported a conductivity of 8 $x 10^{-4} \mathrm{~S} \mathrm{~cm}^{-1}$ for a polymer electrolyte containing amorphous PEO and 50\% PC. The conductivity of the polymer electrolyte $(\mathrm{PEO})_{20} \mathrm{LiAsF}_{6}$ has been shown to be considerably increased by incorporating esters such as Diethyl phthalate and dioctyl sebacate as plasticizers [16]. Tarascon et al. [17] investigated a plastic 
rechargeable lithium-ion battery employing dibutylphthalate (DBP) as a plasticizer in the copolymer electrolyte consisting of PVDF-HFP. The present study deals with the fabrication of polymer films taking PEO as the matrix, $\mathrm{LiAsF}_{6}$ as the lithium salt and various combinations of dibutyl sebacate (DBS) and EC (ethylene carbonate) as plasticizers and evaluation of suitable compositions based on lithium ion conductivity by AC-impedance techniques.

\section{Experimental}

PEO (Aldrich, USA) with average molecular weight of $4 \times 10^{6}$ was dried overnight at $50^{\circ} \mathrm{C}$ under vacuum and $\mathrm{LiAsF}_{6}$ (Aldrich, USA) was used without further purification. Acetonitrile (Merck, Germany) was purified and stored over dry $4 \mathrm{~A}^{\mathrm{o}}$ molecular sieves (Union Carbide, USA). DBS and EC (Merck) were used without further purification. Appropriate amounts of PEO and $\mathrm{LiAsF}_{6}$ in the weight ratio of $8: 1$ were dissolved in acetonitrile with various mole percentages of DBS and EC. The solution was then stirred continuously until the mixture took on a homogeneous viscous liquid appearance. The mixture was then immediately cast on to a Teflon mould inside a dry box and the acetonitrile allowed to evaporate completely. This procedure provided mechanically stable, free-standing and flexible films of thickness from 50 to $200 \mu \mathrm{m}$.

X-ray diffractograms of the electrolyte films were recorded using $\mathrm{Cu}-\mathrm{K} \alpha$ radiation (Jeol JDX 8030, X-ray Diffractometer, Japan) for $2 \theta$ values between 3 to $65^{\circ}$. Conductivity measurements were made for the polymer electrolytes by an AC two-terminal method using EG\&G Princeton Applied Research (PAR) Model 6310 Electrochemical Impedance Analyzer over a frequency range of 10 $\mathrm{Hz}$ and $100 \mathrm{KHz}$. The polymer electrolyte film was sandwiched between stainless-steel ion-blocking electrodes, each of surface area $0.95 \mathrm{~cm}^{2}$, in a springloaded Teflon holder. A thermocouple was kept in close proximity to the electrolyte film for temperature measurements. The cell assembly was inserted into a wide-mouthed glass vessel with a provision for inserting the thermocouple. Film casting and cell assembly were performed inside an evacuated dry box with a provision for inserting a thermometer. The ionic conductivity measurements 
were carried out for films containing different weight ratios of plasticizers and also for a film without plasticizer.

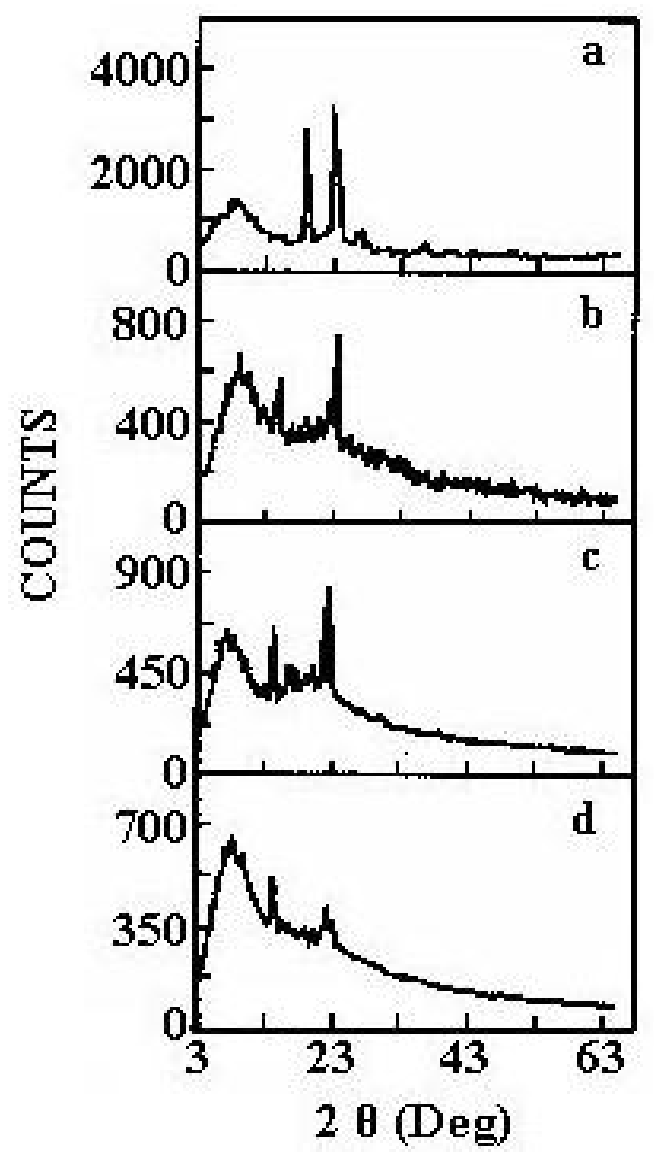

Figure 1. XRD patterns for: a) Pure PEO, b) $\left.(\mathrm{PEO})_{8}-\mathrm{LiAsF}_{6}, \mathrm{c}\right)(\mathrm{PEO})_{8} \mathrm{LiAsF}_{6-}$ $\left.(\mathrm{DBS})_{0.4} ; \mathrm{d}\right)(\mathrm{PEO})_{8}-\mathrm{LiAsF}_{6}-(\mathrm{DBS})_{0.4}-(\mathrm{EC})_{0.1}$ 


\section{Results and discussion}

\section{XRD measurements}

Respective XRD patterns obtained for pure PEO, $(\mathrm{PEO})_{8} \mathrm{LiAsF}_{6},(\mathrm{PEO})_{8^{-}}$ $\mathrm{LiAsF}_{6}-(\mathrm{DBS})_{0.4}$ and $(\mathrm{PEO})_{8}-\mathrm{LiAsF}_{6}-(\mathrm{DBS})_{0.4}(\mathrm{EC})_{0.1}$ films are shown in Fig. 1 (a-d). Well-defined crystalline peaks observed for PEO show the presence of a crystalline phase in a significant proportion. The patterns obtained for the electrolyte films $(\mathrm{PEO})_{8}-\mathrm{LiAsF}_{6}$ (Fig. 1b) containing DBS also exhibit crystalline peaks, but the intensity of the peaks decreases and a broad spectrum appears as the plasticizer concentration is increased. This implies that the amorphous nature of the film increases as a function of concentration of the plasticizers. It is also observed that the $(\mathrm{PEO})_{8}-\mathrm{LiAsF}_{6}$ complex with 0.4 mol of DBS and 0.1 mole of EC is devoid of crystalline peaks and exhibits only a broad spectrum (Fig. 1d), which shows that this composition consists predominantly of an amorphous phase [18].

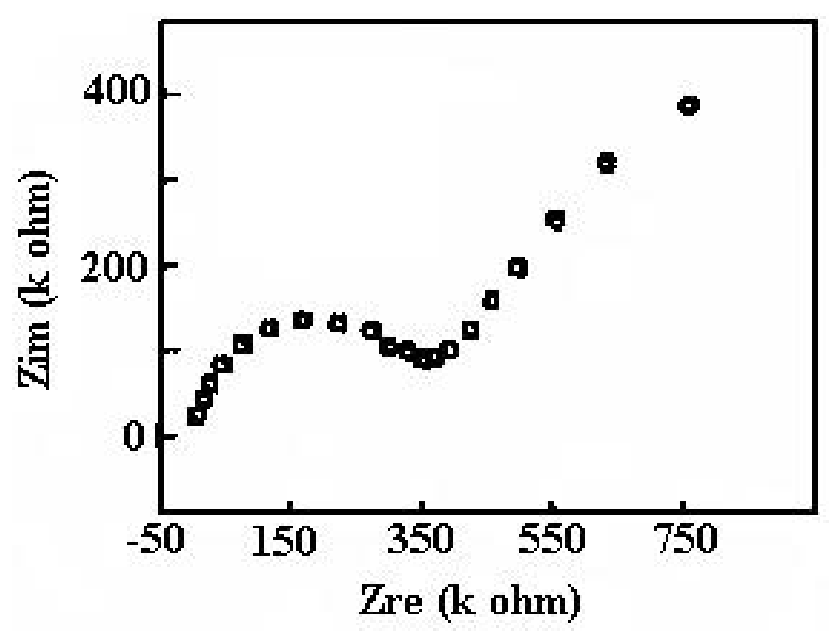

Figure 2. AC response for the electrolyte film $(\mathrm{PEO})_{8}-\mathrm{LiAsF}_{6}$

\section{Conductivity measurements}

The AC response for the electrolyte film $(\mathrm{PEO})_{8}-\mathrm{LiAsF}_{6}$ is depicted in Fig. 2. The high frequency semicircle yields information about the properties of the electrolyte such as bulk resistance, $R_{b}$, and bulk capacitance, $C_{b}$, which arise from the migration of lithium ions and the dielectric polarization of the polymer film, respectively. In the low frequency response region, the appearance of the non- 
vertical spike is attributed to the additional capacitance and resistance contribution arising out of dielectric relaxation and ion trapping in the $(\mathrm{PEO})_{8^{-}}$ $\mathrm{LiAsF}_{6}$ complex network [18]. The structure of DBS, which has been chosen as a plasticizing agent to the polymer electrolyte, is shown in Fig. 3. It is a low molecular weight aprotic polar additive with a high dielectric constant. The two oxygen sites in the ester linkages can provide co-ordination sites for $\mathrm{Li}^{+}$ion conduction through the film [16]. The conductivity studies were taken for $(\mathrm{PEO})_{8}-\mathrm{LiAsF}_{6}$ with different mole ratios of dibutyl sebacate. Typical impedance diagram for $(\mathrm{PEO})_{8}-\mathrm{LiAsF}_{6}-(\mathrm{DBS})_{0.4}$ is shown in Fig. 4. Addition of DBS increases the ionic conductivity form $5.98 \times 10^{-7} \mathrm{~S} / \mathrm{cm}$ to $10^{-6} \mathrm{~S} / \mathrm{cm}$ range. It may be due to the presence of conjugated double bonds in the sebacate ester group that enhances the donor capacity of oxygen and thereby facilitates the formation of ion-ester group coordination through EO units of PEO network bearing the flexible backbone. Further addition of DBS results only a marginal increase in conductivity. The film containing 0.4 mole ratio of DBS showed an optimum conductivity and good mechanical stability. By considering (PEO) ${ }_{8}$ $\mathrm{LiAsF}_{6}-(\mathrm{DBS})_{0.4}$ as the base material, EC with different moles were incorporated into the polymer electrolyte. EC is a high dielectric and viscous solvent. From the impedance measurements made for the complex $(\mathrm{PEO})_{8}-\mathrm{LiAsF}_{6}-(\mathrm{DBS})_{0.4}$ containing different mole ratios of $\mathrm{EC}$, it was found that the electrolyte containing 0.1 mole of EC showed the highest conductivity, as evident from Fig. 5.

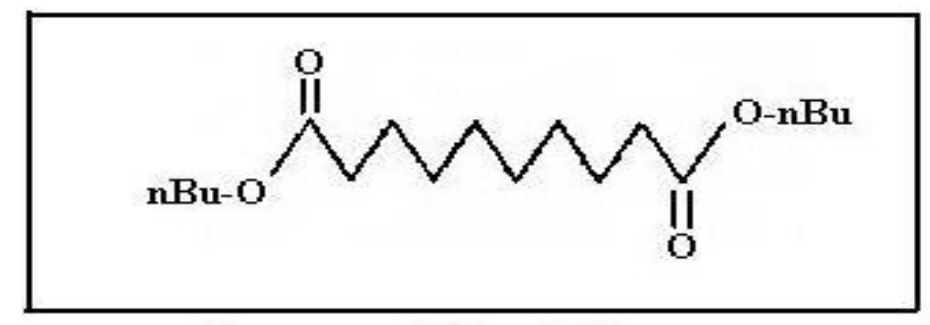

\section{Structure of Dibutyl Sebacate}

Figure 3. Structure of dibutyl sebacate (DBS). 


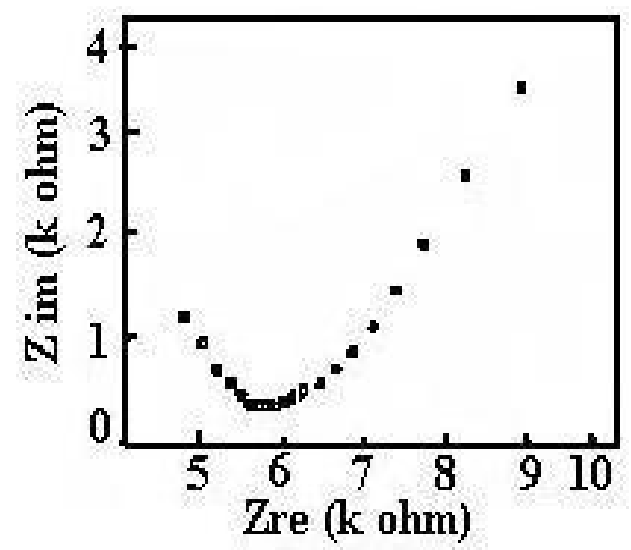

Figure 4. Impedance diagram for $(\mathrm{PEO})_{8}-\mathrm{LiAsF}_{6}-(\mathrm{DBS})_{0.4}$

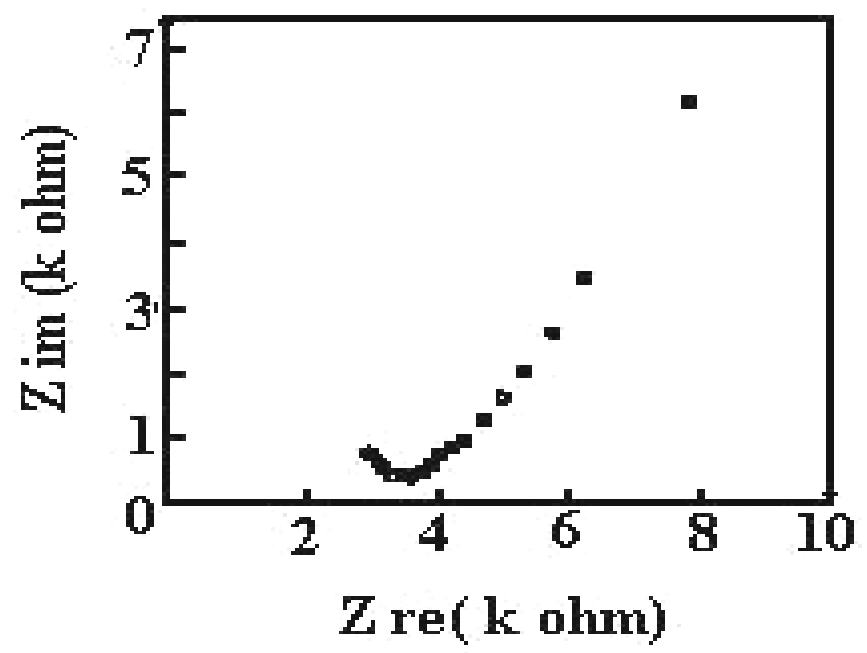

Figure 5. Impedance diagram for $(\mathrm{PEO})_{8}-\mathrm{LiAsF}_{6}-(\mathrm{DBS})_{0.4}-(\mathrm{EC})_{0.1}$.

\section{Temperature dependence of conductivity}

Impedance diagrams for $(\mathrm{PEO})_{8}-\mathrm{LiAsF}_{6}$ and $(\mathrm{PEO})_{8}-\mathrm{LiAsF}_{6}-(\mathrm{DBS})_{0.4}(\mathrm{EC})_{0.1}$ were obtained at different temperatures, such as 40,55 and $65{ }^{\circ} \mathrm{C}$ and are given in Figs. 6-8. Curves of $\log _{10} \sigma$ vs. 1/T (Fig. 9) show the temperature dependence of conductivity on $(\mathrm{PEO})_{8}-\mathrm{LiAsF}_{6}$ and on $(\mathrm{PEO})_{8}-\mathrm{LiAsF}_{6}-(\mathrm{DBS})_{0.4}(\mathrm{EC})_{0.1}$. It is obvious that the temperature dependence of the conductivity $(\sigma)$ on these systems obeys the Arrhenius Law. The activation energy $\left(E_{a}\right)$ for both systems is calculated from the slope of the corresponding curves. The $\mathrm{E}_{\mathrm{a}}$ for $(\mathrm{PEO})_{8}-\mathrm{LiAsF}_{6}$ is $10 \mathrm{~kJ} / \mathrm{mol}$, whereas the $\mathrm{E}_{\mathrm{a}}$ for $(\mathrm{PEO})_{8}-\mathrm{LiAsF}_{6}-(\mathrm{DBS})_{0.4}(\mathrm{EC})_{0.1}$ is reduced 
considerably to $0.81 \mathrm{~kJ} / \mathrm{mol}$, thus facilitating the lithium ion transport within the polymer matrix.

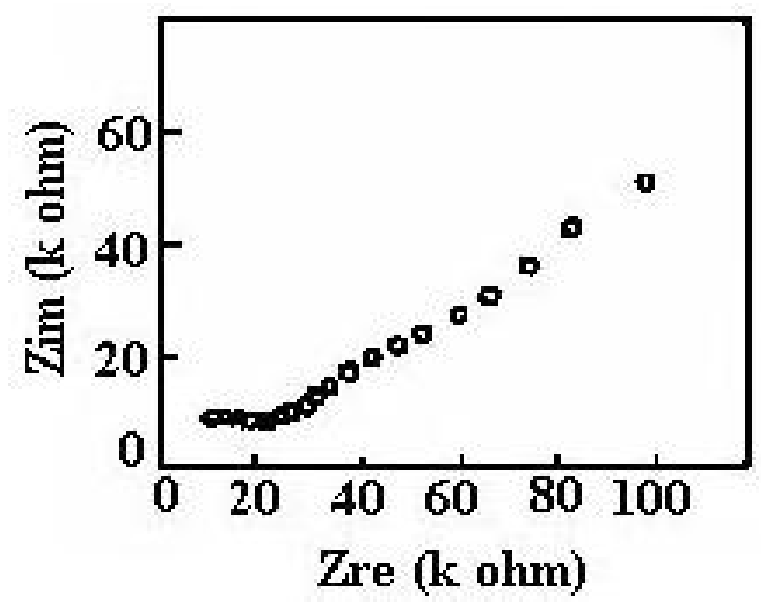

Figure 6. Impedance diagram for $(\mathrm{PEO})_{8}-\mathrm{LiAsF}_{6}$ at $40{ }^{\circ} \mathrm{C}$.

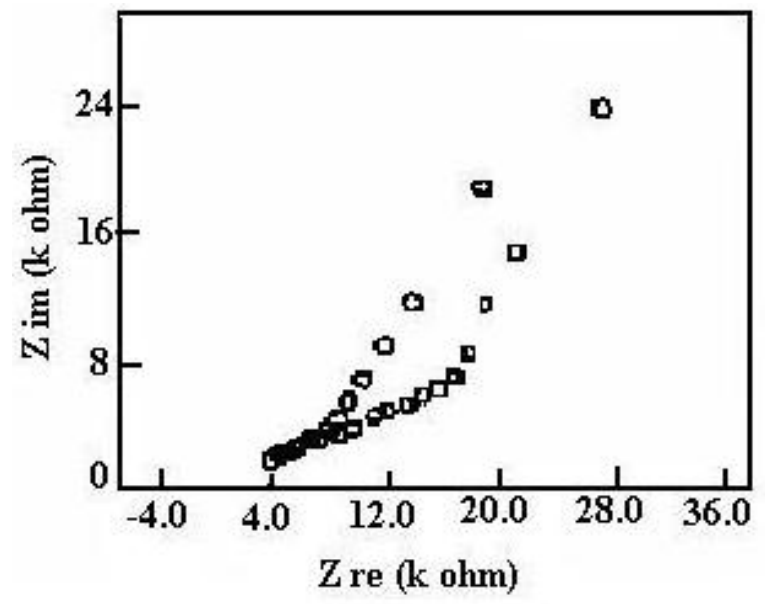

Figure 7. Impedance diagram for $(\mathrm{PEO})_{8}-\mathrm{LiAsF}_{6}$ at $55{ }^{\circ} \mathrm{C}(\square)$ and at $65{ }^{\circ} \mathrm{C}(\mathrm{O})$. 


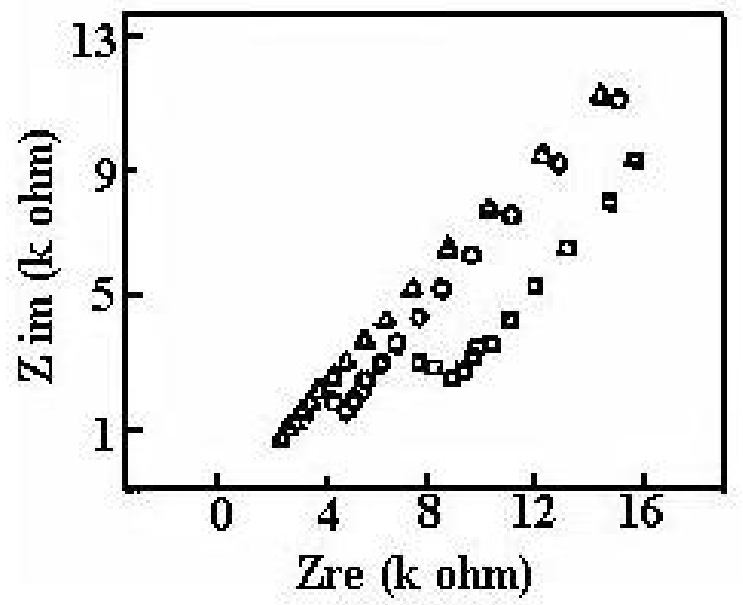

Figure 8. Impedance diagram for $(\mathrm{PEO})_{8}-\mathrm{LiAsF}_{6}-(\mathrm{DBS})_{0.4}-(\mathrm{EC})_{0.1}$ at $45{ }^{\circ} \mathrm{C}(\square)$, at 55 ${ }^{\circ} \mathrm{C}$ and at $65^{\circ} \mathrm{C}(\Delta)$.

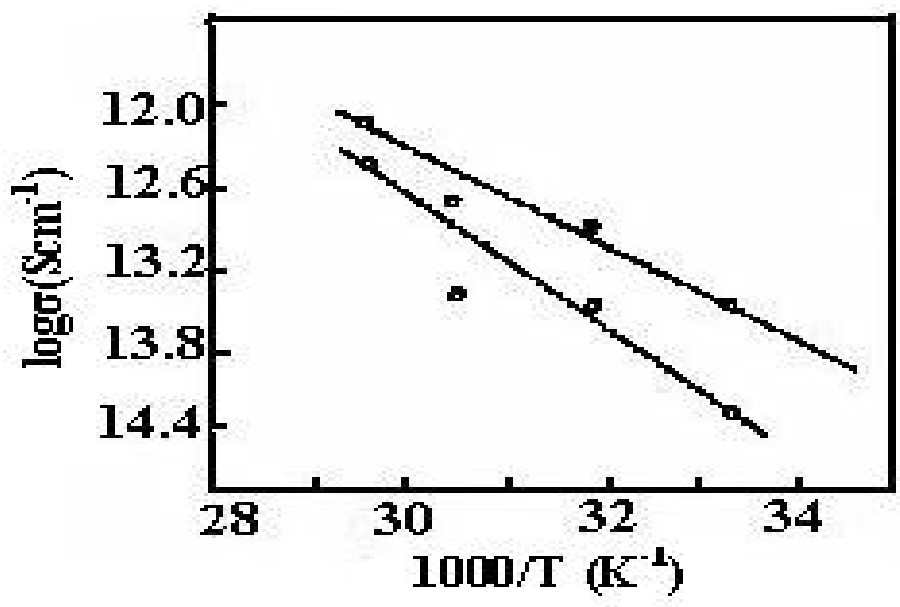

Figure 9. Arrhenius plot for (a) $(\mathrm{PEO})_{8}-\mathrm{LiAsF}_{6}$ and (b) $(\mathrm{PEO})_{8}-\mathrm{LiAsF}_{6}-(\mathrm{DBS})_{0.4^{-}}$ $(\mathrm{EC})_{0.1} \mathrm{AC}$ impedance spectrum for $(\mathrm{PEO})_{8}-\mathrm{LiAsF}_{6}$ electrolyte.

\section{Conclusions}

We conclude by saying that the polymer electrolyte $(\mathrm{PEO})_{8}-\mathrm{LiAsF}_{6}$ containing plasticizers in the composition $0.4 \mathrm{~mol}$ of DBS and $0.1 \mathrm{~mol}$ of EC produces a free-standing film with optimum lithium ion conductivity. The increase in the conductivity with DBS and EC addition of the polymer electrolyte is explained in terms of enhancement of the amorphous phase with concomitant reduction in the energy barrier to the segmental motion of lithium ions. This conforms to the observed low value of the activation energy calculated from the Arrhenius plot. 


\section{References}

1. Armand, Solid State Ionics 69 (1994) 309.

2. Scrosati, in: B.V.R. Chowdari et al. (Eds.), Solid State Materials, World Scientific, Singapore, 1994, pp. 111-118.

3. R. Sorenson, T. Jacobsen, Electrochim. Acta 27 (1982) 1671.

4. Aihara, M. Kodama, K. Nakahara, H. Okise, K. Marata, J. Power Sources 65 (1997) 143-147.

5. $\quad$ E. Fenton, J.M. Parker, P.V. Wright, Polymer 14 (1973) 589.

6. B. Armand, J.M. Chabagno, M. Duclot, in: P. Vahista, J.N. Mundy, G.K. Shenoy (Eds.), Fast Ion Transport in Solids, Elsevier, North Holland, New York, 1979, p. 131.

7. A. Ratner, in: J.R. Maccallum, C.A. Vincent (Eds.), Polymer Electrolyte Reviews-I, Elsevier, New York, 1987, p. 173.

8. C.A. Vincent, Electrochemical Science and Technology of Polymers-2, Elsevier, New York, 1990, p. 47.

9. C. Berthier, W. Gorecki, M. Minier, M.B. Armand, J.M. Chabagno, P. Rigand, Solid State Ionics 11 (1983) 91.

10. E. Tsuchida, H. Ohno, K. Tsunemi, N. Kobayashi, Solid State Ionics 11 (1983) 227.

11. M. Gorecki, R. Andreani, C. Berthier, M.B. Armand, M. Mali, J. Roos, D. Brinkmann, Solid State Ionics 18 (1986) 295.

12. F.M. Gray, in: J.R. Maccallum, C.A. Vincent (Eds.), Polymer Electrolyte Review-I, Elsevier, New York, 1987, p. 139.

13. I.E. Kelly, J.R. Owen, B.C.H. Stelle, J. Power Sources 14 (1985)13.

14. M.Z.A. Munshi, B.B. Owens, Solid State Ionics 26 (1988) 41.

15. D.G.H. Ballard, P. Chesire, T.S. Mann, J.E. Przeworski, Macromolecules 23 (1990) 1256.

16. C.W. Walker Jr., M. Salomon, J. Electrochem. Soc. 140 (1993) 3409.

17. J.M. Tarascon, A.S. Gozdz, C. Schmutz, F. Shokoohi, P.C. Warren, in : B.V.R. Chowdari (De.), Proceedings of the $10^{\text {th }}$ International Conference on Solid State Ionics, 86-88, 1996, 49. 
18. P.V. Wright, C.C. Lee, Polymer 23 (1982) 681. 